\title{
PULMONARY HAEMORRHAGE WITH EXTENSIVE GLOMERULAR DISEASE OF THE KIDNEY
}

\author{
BY \\ R. H. HEPTINSTALL AND M. V. SALMON \\ From the Department of Pathology, St. Mary's Hospital, London
}

(RECEIVED FOR PUBLICATION JULY 26, 1958)

\begin{abstract}
Under the title "Haemorrhagic and Interstitial Pneumonia with Nephritis," Parkin, Rusted, Burchell, and Edwards (1955) described seven cases in which gross haemorrhage into the alveoli of the lungs occurred in association with a severe glomerular lesion of the kidneys. The present paper describes three cases seen at St. Mary's Hospital during the past four years in which a similar association was found, and an attempt is made to consider the nature of such an association.
\end{abstract}

\section{Case Histories}

Case 1.-This patient, a housewife, was first seen in 1948, then aged 61 years, because of osteoarthritis of the knees. She was not seen again till 1956 when she attended hospital because of vomiting, nausea, and abdominal pain of one year's duration. She had been short of breath for five weeks. A diagnosis of hiatus hernia, confirmed by barium meal, was made, the haemoglobin at this time being $13.3 \mathrm{~g} . / 100 \mathrm{ml}$. During the next seven weeks she became weaker and vomiting accompanied by abdominal pain became a daily occurrence. Her relatives remarked that she had been having dark stools for four weeks. She showed a marked personality change, being now depressed instead of cheerful. There was no relevant family history.

On admission to hospital she was dyspnoeic and pale with no evidence of cyanosis. Arthritic changes were present in both knees. There was a moderate blowing systolic murmur over the whole heart, especially the apex, the heart rate being $100 /$ minute and regular. There was no finger clubbing and no fever; blood pressure $165 / 95 \mathrm{~mm}$. Hg; Hb 8.1 g./100 ml.; R.B.C. $3.0 \times 10^{6} /$ c.mm. ; P.C.V. $=30$, M.C.V. $=$ 100 c $\mu$, M.C.H. $=27 \gamma \gamma$, M.C.H.C. $27 \%$. The urine contained much protein, moderate numbers of red blood cells, and a few casts. A specimen of stool was weakly positive for occult blood. Investigations carried out during the next few days were: blood urea $370 \mathrm{mg}$. $/ 100 \mathrm{ml}$.; plasma protein $5.3 \mathrm{~g} . / 100 \mathrm{ml}$. (albumin 2.2 g., globulin $3.1 \mathrm{~g}$.) ; serum cholesterol $100 \mathrm{mg} . / 100 \mathrm{ml}$. ; serum electrolytes (mEq./litre) $\mathrm{Na}$

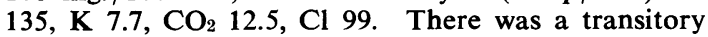
symptomatic improvement after intravenous dextrose and sodium lactate, but after a haemoptysis of a few ounces of blood on December 11 death occurred the following day.
Relevant Necropsy Findings.-Body weight was $68 \mathrm{~kg}$. The heart weighed $395 \mathrm{~g}$. with slight ventricular thickening and some tiny vegetations on the mitral valve. There was no stenosis of the mitral valve. The trachea and bronchi contained frothy blood. Externally the lungs, which were large and bulky, showed many purple areas. On section there was much fluid blood throughout the lung with some firmer granular dark areas. There was no obvious source of haemorrhage. The subcapsular surfaces of the kidneys (right 168 g., left 125 g.), which were smooth, showed petechiae. On section there was red and white cortical mottling, the rest being pale with a few medullary petechiae.

Microscopic Changes. - The most conspicuous change was the presence in alveoli of large numbers of red blood cells with or without fibrin. The change was diffuse except that small scattered areas showed very few red blood cells. Some of the fibrin showed evidence of organization and a certain number of alveoli showed watery fluid. Siderophages were present in alveoli but were not so numerous as in the following case. Interalveolar septa showed only scattered abnormalities consisting of fibrous thickening or proliferation of the lining cells. The reticulin and elastic distribution in the septa was not materially abnormal and no septal necroses were found. There were no changes in bronchial or pulmonary arteries and there was no evidence of infection.

Almost all glomeruli were affected, although to different degrees. Fibrinoid necrosis of the tufts was a frequent finding (Fig. 1), affecting usually only a part of the tuft but sometimes affecting the whole. In the latter instances the necrosis was continuous with a similar change in the afferent arteriole. Proliferation of endothelial and epithelial cells was frequent in the tufts, and localized areas of hyalinization or fibrosis were present in some. Some appeared to be completely sclerotic. There was considerable proliferation of cells lining Bowman's capsule and well-developed crescents, some of which showed organization, were conspicuous.

There was much loss of proximal convoluted tubules whilst others showed dilatation. Red blood cells and casts were frequent, whilst some tubules showed iron pigment.

Interlobular arteries showed the changes of polyarteritis nodosa in an acute stage with fibrinoid 


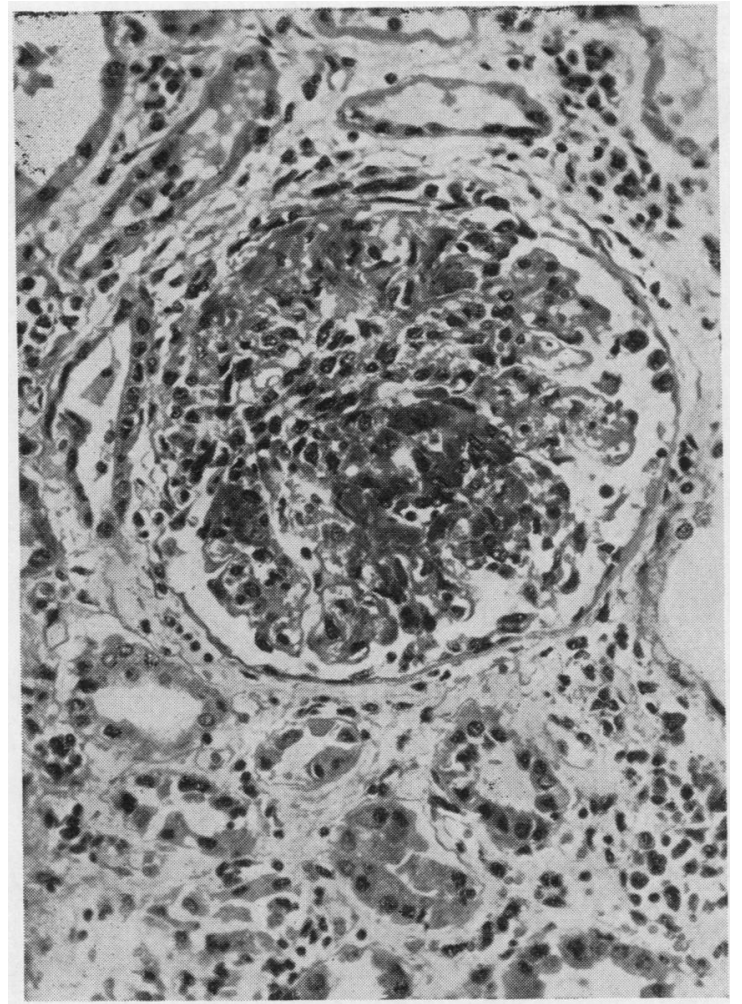

FIG. 1.-Glomerular tuft with fibrinoid necrosis in Case 1. Haematoxylin and eosin, $\times 240$.

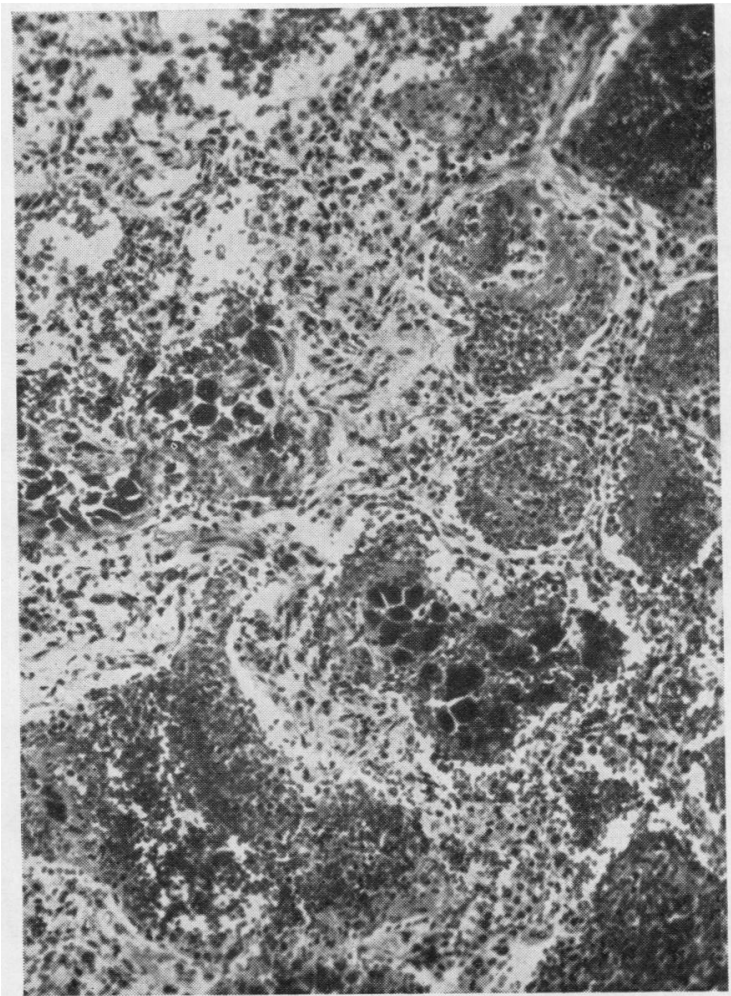

Fig. 3.-Lung with red blood cells, siderophages, and organizing fibrin in alveoli in Case 2. Haematoxylin and eosin, $\times 140$.

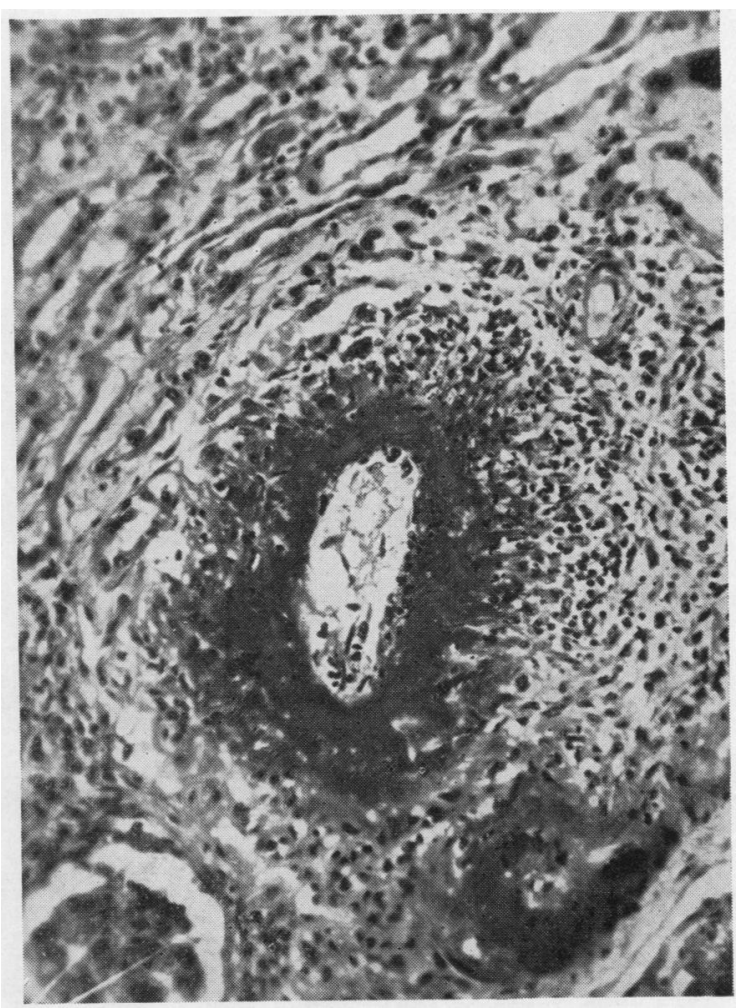

FIG. 2.-Interlobular artery with fibrinoid necrosis and cellular reaction in Case 1. Haematoxylin and eosin, $\times 170$.

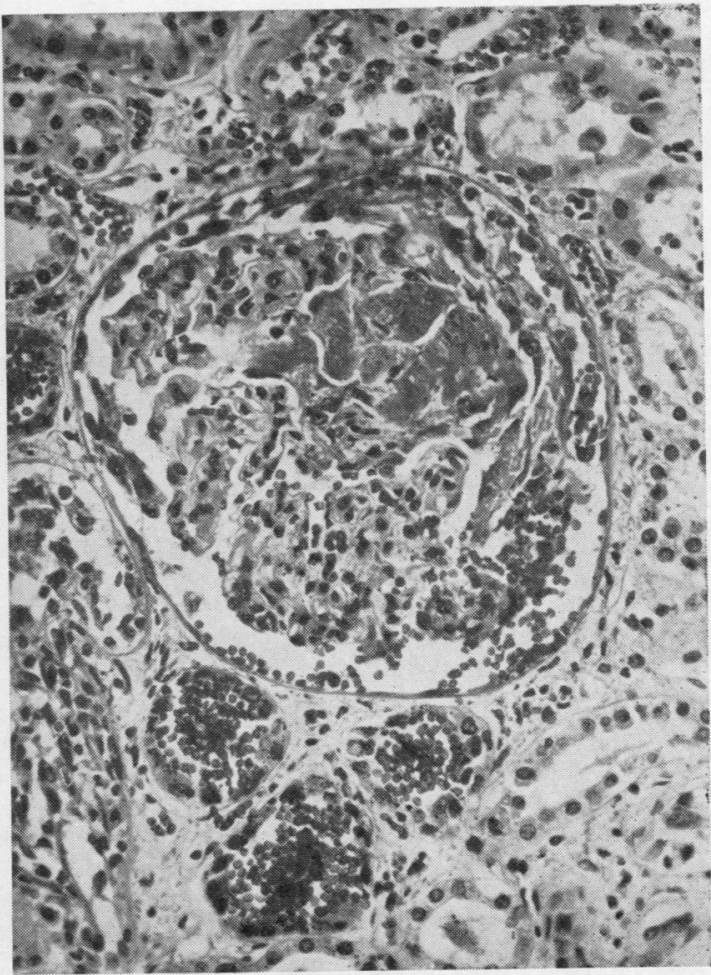

FIG. 4. Glomerulus with focus of fibrinoid necrosis and red blood cells in Bowman's space in Case 2. Haematoxylin and eosin, $\times 240$. 
necrosis and cellular reaction (Fig. 2). Other vessels of this size showed much fine intimal collagenous thickening. Some afferent arterioles showed fibrinoid necrosis continuous with necrosed tufts. Several arcuate arteries showed fibro-elastic intimal thickening.

In the interstitium there were large numbers of plasma cells and a fine fibrosis. The arteries of the spleen showed acute polyarteritis nodosa.

Case 2.-This patient, a man aged 23 years, felt off colour and short of breath in mid-July, 1954. He developed a slight cough and brought up fresh blood on several occasions. The greatest amount of blood was $1 \mathrm{oz}$. but usually it was merely streaking in the sputum. At the beginning of September he complained of indigestion and vomited on one occasion. His breathlessness increased. In the middle of September he was found to have moderate proteinuria, and white and red blood cells and granular casts in the urine, which was sterile. Other investigations showed: $\mathrm{Hb} 8 \mathrm{~g} . / 100 \mathrm{ml}$.; R.B.C.s $2.01 \mathrm{~m}$./c.mm. ; W.B.C. $11,800 /$ c.mm. $(80 \%$ polymorphs), platelets $80,000 / \mathrm{c} . \mathrm{mm}$. ; blood urea 90 $\mathrm{mg}$. $/ 100 \mathrm{ml}$. ; serum protein $5.83 \mathrm{~g} . / 100 \mathrm{ml}$. (albumin $4.93 \mathrm{~g}$., globulin $0.9 \mathrm{~g}$.) ; indirect serum bilirubin 0.4 mg. $/ 100 \mathrm{ml}$. A transfusion of packed red cells was attempted, but a shivering attack caused this to be abandoned.

He was admitted to St. Mary's Hospital on September 27, 1954, in a desperately ill condition. There was no relevant family history and nothing important in the past history except that as a boy he used to get unexplained pyrexia and a vague history of nocturnal frequency of micturition. He was pale, slightly pyrexial, but not oedematous. The pulse was regular, there were no cardiac murmurs, and blood pressure was $130 / 70 \mathrm{~mm}$. Hg. Chest radiographs showed increased shadowing obscuring the mid-zones peripherally and extending into the upper zones which showed coarse miliary mottling. Investigations carried out were: Hb $3.7 \mathrm{~g} . / 100 \mathrm{ml}$.; R.B.C. $1.55 \mathrm{~m} . /$ c.mm. ; W.B.C. $11,000 /$ c.mm. $(85 \%$ polymorphs); platelets $155,000 / \mathrm{c} . \mathrm{mm}$.; blood urea $184 \mathrm{mg} . / 100 \mathrm{ml}$.; serum protein $5.6 \mathrm{~g} . / 100 \mathrm{ml}$. (albumin 3.75 g., globulin 1.85 g.). The urine contained a large amount of protein, abundant red blood cells, a moderate number of pus cells, and granular casts in the deposit. He was treated with intravenous sodium bicarbonate, blood transfusions, and, because of the possibility of miliary tuberculosis, with streptomycin and isoniazid. The blood urea continued to rise and two days later was $220 \mathrm{mg}$./ $100 \mathrm{ml}$. He coughed up large amounts of bloodstained sputum and died four days after admission.

Relevant Necropsy Findings (Dr. R. R. Wilson).Body weight was $62 \mathrm{~kg}$. The heart weighed $456 \mathrm{~g}$. with some left ventricular thickening but no valvular defects. The lungs were dark and solid throughout. In addition there were numerous small petechial haemorrhages under the pleura. There was bloodstained fluid in the bronchi, but no obvious cause for the haemorrhage. Both kidneys (right $196 \mathrm{~g}$., left 228 g.) were swollen, soft, and congested with petechial haemorrhages under the capsule and on the cut surface.

Apart from some petechial haemorrhages in the white matter of the brain, there were no other remarkable changes.

Microscopic Changes.-The main change in the lung consisted of large numbers of red blood cells with small numbers of polymorphs in the alveoli, sometimes associated with fibrin which in places showed organization by fibroblasts. There were also large numbers of haemosiderin-containing macrophages (siderophages) in alveoli, sometimes being found in organizing fibrin (Fig. 3). These changes were diffuse throughout the lung. In some alveoli there was oedema fluid, although this was not conspicuous, and occasional hyaline membranes were seen. Interalveolar septa usually showed no change, but some showed dilated capillaries and others focal fibrous thickening. The reticulin pattern of the septa was preserved and the elastica of both septa and blood vessels showed no remarkable change. The septa showed no striking increase in cells and there were no recognizable necroses. Occasionally siderophages were incorporated into the septa. Pulmonary and bronchial arteries were normal. Apart from containing red blood cells, bronchi and bronchioles were normal.

All the glomeruli were affected and showed changes of approximately the same age. The tufts were reduced in size and showed an increase in hyaline material and fine collagen. There was some cellular proliferation in the tufts, and scattered glomeruli showed intracapillary thrombosis which in places was continuous with the capillary wall and resembled fibrinoid necrosis (Fig. 4). There was generalized proliferation of the epithelium lining Bowman's capsule, producing epithelial crescents encroaching considerably on the capsular space (Fig. 5). There was no organization of crescents. Red blood cells were frequent in the capsular space.

Some proximal tubules were lined by a low type of epithelium and large numbers of red blood cells were present in tubules of all types.

Apart from a thrombus in a large renal vein there were no vascular changes. In particular there were no changes of acute arteritis and no evidence of healed arteritis.

Interstitial tissue showed no changes.

Case 3.-A 41-year-old farmer noticed some malaise during the early part of 1957 . In October of 1957 he was admitted to hospital in Ireland for six weeks because of shortness of breath on exertion and dyspnoea while lying flat in bed. At this time there was no cough, no chest pain, and no ankle oedema. He had a haemoptysis at this time and was told while in hospital that he had blood in the urine. During his stay in hospital he had pain in the left loin lasting for three days. Shortly after discharge he developed ankle oedema. 


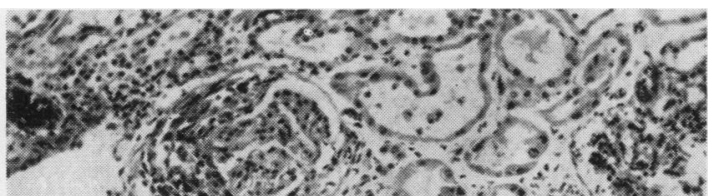
(n) 0 .

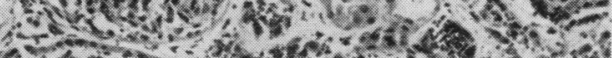

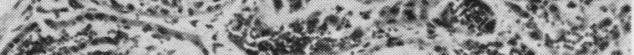

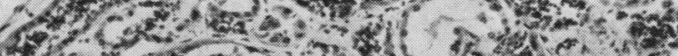

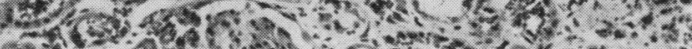

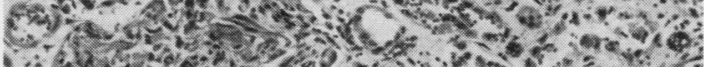

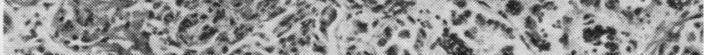

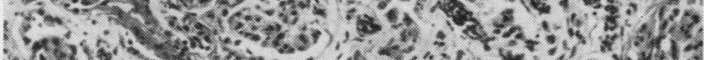
- $\begin{aligned} & 3 \\ & 3\end{aligned}$

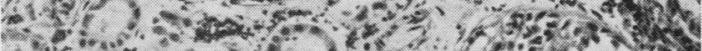

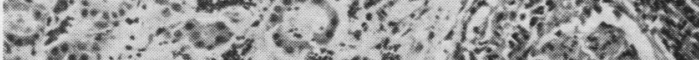

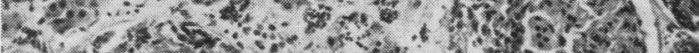

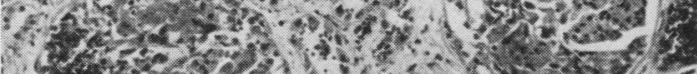

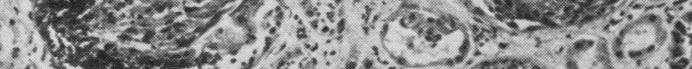

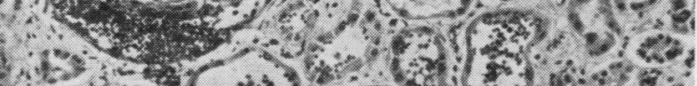

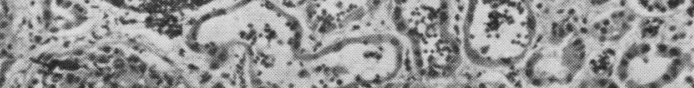

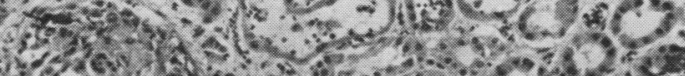
$4(6)$ (3)

FIG. 5.-Glomeruli to show crescent formation in Case 2. Haematoxylin and eosin, $\times 100$.

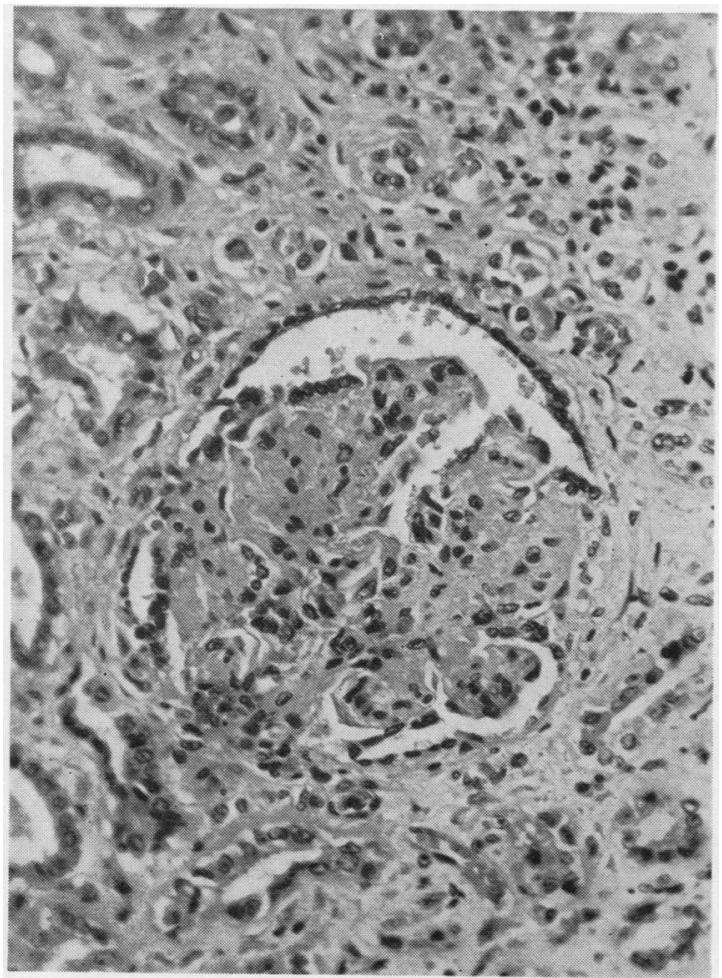

Fig. 7.-Glomerulus with hyalinization in Case 3. Haematoxylin and eosin, $\times 240$.

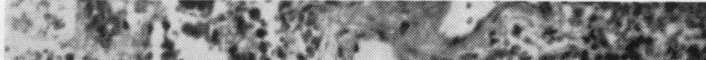

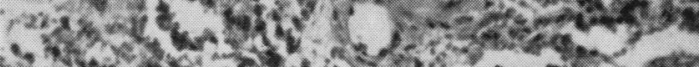

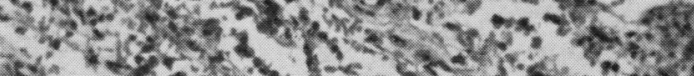

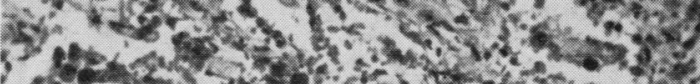

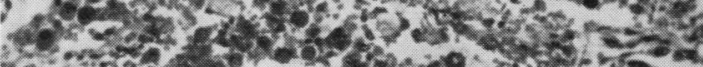
¿15.

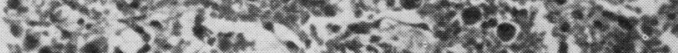

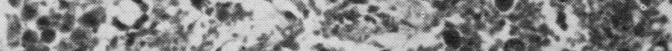

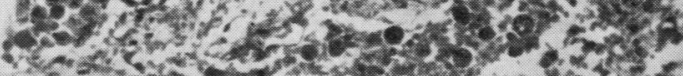
1. 200 -

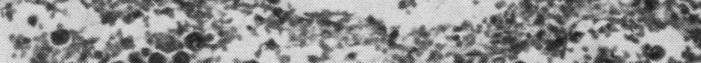
*.

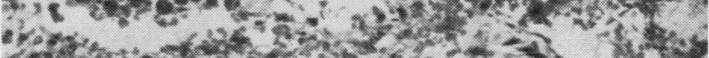

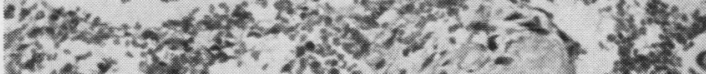

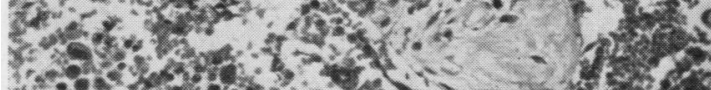

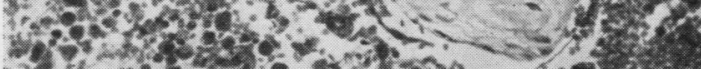

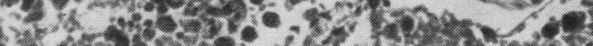

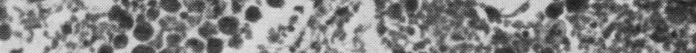

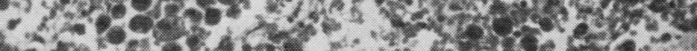

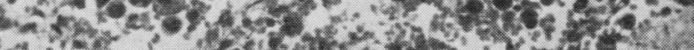

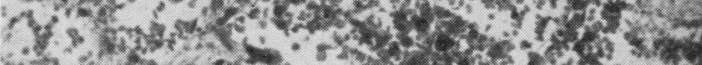

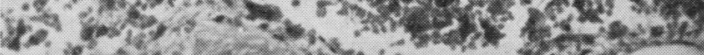

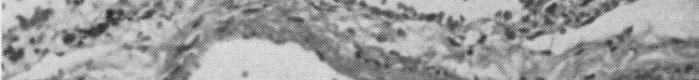

FIG. 6.-Lung with red blood cells and siderophages in alveoli in Case 3. Haematoxylin and eosin, $\times 140$.

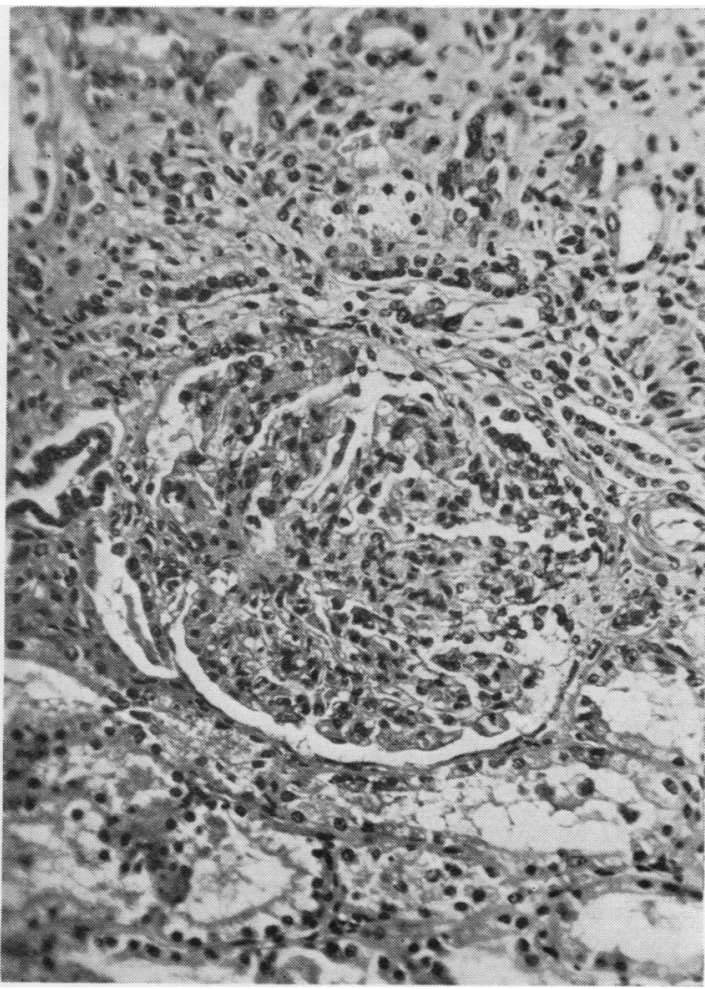

Fig. 8.-Glomerulus with cellular proliferation in Case 3. Haematoxylin and eosin $\times 170$. 
During the early part of January, 1958, he developed a productive cough with sputum containing a considerable quantity of bright red blood. He was admitted to St. Mary's Hospital on January 21, 1958.

He was a tall, muscular, cheerful man with no relevant family history except that his father, who died at 66 years, had suffered from asthma. Eight brothers and sisters were alive and well. There was no history of rheumatic fever, scarlet fever, chest disease, or nephritis. He had suffered from frequency of micturition, both day and night, since childhood, but this had not been worse recently. There was no recent loss of weight and appetite had been good up till three days before admission.

On examination he was moderately dyspnoeic at rest, there was no cyanosis and no clubbing. The pulse rate was 120 and regular ; blood pressure 180 / $110 \mathrm{~mm} . \mathrm{Hg}$; the heart enlarged to the left with a blowing apical systolic murmur and a loud middiastolic sound. There was both ankle and sacral oedema and a jugular venous pressure of $4 \mathrm{~cm}$. The ocular fundi were normal. Investigations performed: E.S.R. (Westergren) $80 \mathrm{~mm}$. in one hour; serum cholesterol $208 \mathrm{mg}$. $/ 100 \mathrm{ml}$; total serum protein $5.5 \mathrm{~g} . / 100 \mathrm{ml}$. with albumin $50 \%$ of total ; blood urea $180 \mathrm{mg} . / 100 \mathrm{ml}$. ; Hb $6.7 \mathrm{~g} . / 100 \mathrm{ml}$. Urine: protein 3.2 g. $/ 24 \mathrm{hr}$., with $2.7 \times 10^{6}$ leucocytes and nonsquamous epithelial cells per hour. A test for occult blood in the stool was negative.

During the first few days in hospital the patient produced between 3 and $5 \mathrm{oz}$. heavily blood-stained sputum daily. A chest radiograph showed considerable cardiac enlargement and generalized pulmonary oedema. He was given digitalis to control the cardiac failure and was transfused with 2 pints of packed red blood cells. There was a marked lessening of dyspnoea and signs of cardiac failure disappeared. Linear haemorrhages, however, developed in the retina and the blood pressure rose to $200 / 140 \mathrm{~mm}$. $\mathrm{Hg}$, at which time he was treated with mecamylamine and reserpine. Blood cultures were sterile and no organisms were grown from the urine.

In spite of a 3,000 calories low-protein diet and 3 litres of fluid daily he became increasingly acidotic and the blood urea continued to rise. Oral feeding was superseded by intravenous drip therapy.

On February 6, 1958, he was started on prednisone, $60 \mathrm{mg}$. daily, for two weeks, after which time the dosage was reduced to $30 \mathrm{mg}$. daily. Two days after the start of this therapy haemoptysis ceased and never recurred.

Following a six-hour dialysis on February 9 (Dr. Victor Wynn) the blood urea was reduced from 290 mg./100 ml. to $80 \mathrm{mg}$. $/ 100 \mathrm{ml}$, and for 11 days he was much improved. However, because of the fall in urinary output and the rising blood urea, a further dialysis was performed on February 20, but death occurred the following day.

Relevant Necropsy Findings.-Body weight was 78 $\mathrm{kg}$. The heart weighed $580 \mathrm{~g}$. There was a slight fibrinous pericarditis and hypertrophy of the left ventricle. No valvular defects were present. The lungs were heavy and bulky. The lower lobes showed subpleural purplish areas. On the cut surface there were numerous firm red-brown areas superimposed on a rather moist, moderately dark background. Blood was present in the trachea and bronchi. No obvious cause for haemorrhage was found. The right kidney weighed $135 \mathrm{~g}$. and the left $118 \mathrm{~g}$. The left kidney showed some blood outside the capsule (presumably from an unsuccessful needle biopsy of kidney some days before death). Both kidneys were reduced in size and showed thinning of the cortex with finely granular subcapsular surface.

Microscopic Changes.-The most striking changes were the large numbers of red blood cells and siderophages in alveoli (Fig. 6). Organizing fibrin was a frequent finding, siderophages often being embedded in the organizing mass. Inter-alveolar septa showed engorged capillaries and some showed fibrosis, often in continuity with organizing fibrin in the alveoli. The septal reticulin pattern was preserved except in scattered areas which showed patchy bronchopneumonia. The elastica in both septa and blood vessels showed little change. There was no increase in inflammatory cells in septa. There were no pronounced arterial changes.

The alveolar haemorrhages were more pronounced in the lower lobes than elsewhere.

Almost all glomeruli were affected, the degree of involvement varying considerably. Many were completely hyaline, reduced in size, and surrounded by a mantle of collagen. Others showed partial or complete hyalinization, the tuft being covered by proliferating epithelial cells (Fig. 7). Others showed proliferation of endothelial cells in the tufts (Fig. 8), but no fresh necroses were seen and there was no crescent formation.

There was considerable tubular loss, remaining proximal tubules being dilated and containing eosinophilic casts.

Arcuate arteries showed fibro-elastic intimal thickening, sometimes affecting only a part of the circumference. Interlobular arteries showed fine cellular collagenous thickening which was pronounced in most. There were hyaline changes in arterioles. No evidence of polyarteritis nodosa in the acute stage was seen.

There was fine interstitial fibrosis and scattered lymphocytes and plasma cells.

\section{Discussion}

From the clinical point of view the cases showed many similar features. All suffered from abdominal discomfort, dyspnoea, profound anaemia, haemoptysis, and evidence of renal failure. The only haemoptysis in Case 1 occurred the day before death, but in Cases 2 and 3 it was present for two and four months respectively. There was a history of nocturnal frequency of micturition in Case 3 and a vague history of 
frequency in Case 2. The third patient was the only one with any appreciable rise of blood pressure.

At necropsy it was found that all showed enlargement of the heart, the left ventricles being hypertrophied in the absence of any gross valvular defects. There is a fundamental similarity of the renal lesion in Cases 1 and 2, while in Case 3 an older type of change is present. Case 1 represents the necrotizing glomerulitis so frequently associated with polyarteritis nodosa, evidence for the latter being provided by acute arterial lesions in the kidney and spleen. This particular type of renal change was well described by Davson, Ball, and Platt (1948), and the kidney changes in Case 1 conform well to their description. The spectrum of involvement of glomeruli is wide in this case, for at one extreme some have florid tuft necrosis while at the other some are partially or wholly sclerotic. The renal changes in Case 2 are very similar. Nearly all glomeruli are abnormal, necrosis being present in some while most show cellular proliferation in both the tuft and in cells lining Bowman's capsule, with the production of epithelial crescents. Some partially sclerosed glomeruli are seen, but this change is not so pronounced as in Case 1. The main point of difference from the latter case is the absence of acute necrotizing arteritis. The picture is one acceptable as the extracapillary type of subacute glomerulonephritis (Volhard and Fahr, 1914) or rapidly progressive Type 2 nephritis (Ellis, 1942), but more necroses are present in the tufts than are usually seen in this type of glomerulonephritis. There seems little doubt that there is a considerable overlap between this variety of glomerulonephritis and the kidney of polyarteritis nodosa with glomerular lesions, crescent formation and proliferative changes being present in both although more pronounced in the former while tuft necroses are more prominent in the latter. Case 3 showed a renal lesion of chronic glomerulonephritis with in addition evidence of more recent proliferative activity. Evidence of healed necrotizing arteritis was sought, but no convincing changes were found either in the kidney or elsewhere.

With regard to the lung changes, Cases 2 and 3 show the greatest similarities both in the way in which haemoptysis had been present for several weeks before death and also in the pathological picture. Both showed widespread fresh intraalveolar haemorrhage and older changes in the form of iron-containing macrophages and organized fibrin. Case 1 showed a much more recent picture in that most of the haemorrhage was fresh although there was some evidence of older bleeding. In no case was there a necrotizing arteritis nor was there evidence of necrotizing alveolitis nor infiltration of the inter-alveolar septa by inflammatory cells as described in the series of Parkin et al. (1955). Haemorrhage into alveoli is one of the essential features of idiopathic pulmonary haemosiderosis, and because of the essential similarity between the lung changes in this condition and those of the cases under discussion the published cases of idiopathic haemosiderosis were reviewed to see if there was a high incidence of renal lesions.

Idiopathic pulmonary haemosiderosis was first described by Ceelen in 1931, the majority of cases occurring in childhood, although increasing numbers are now being described in adults. Halmágyi, Felkai, Sövényi, Weber, Czipott, Kovács, and Steiner (1956), Borsos-Nachtnebel (1942), Russi and Wingo (1956), and Tait and Corridan (1952) have described patients aged 40 , 38,37 , and 31 years respectively, all of them being men. A further 11 recorded cases affecting people over the age of 19 years have been found. The lungs are heavily impregnated with haemosiderin contained in macrophages in the alveoli, in the septa in relation to fragmented elastica, and in the walls of blood vessels. Both the cause and the source of the haemorrhage remain obscure, the necrotizing arteritis described by Anspach (1939) being exceptional. It seems more likely that the bleeding is from the alveolar capillaries or from bronchopulmonary anastomoses as proposed by Lendrum, Scott, and Park (1950) in mitral stenosis. The aetiology has aroused much speculation, but at the present time no theory advanced has much scientific evidence to substantiate it.

Out of a total of 69 recorded cases of idiopathic pulmonary haemosiderosis, five cases have been found in which a renal lesion was present. Glanzmann and Walthard (1941) described a girl of 13 years with a characteristic history but who in addition had albumin, red blood cells, and casts in urine. At necropsy a renal picture was found which they regarded as focal embolic nephritis, glomeruli showing partial loop necrosis and increased endothelial cells. They attributed this to an attack of scarlatina at 6 years of age. Scheidegger and Dreyfus (1945) described a girl aged 1 year in whom renal changes in life were manifested by a mild proteinuria and red blood cells and casts in the urine. The kidneys showed what the authors described as focal nephritis. Propst (1955) dessribed a focal acute to subacute glomerulonephritis in an 11-year-old boy with the usual lung picture. The description of the renal 
lesions was scanty and little attention was paid to it. Bruwer, Kennedy, and Edwards (1956) described a 12-year-old boy with lung changes of idiopathic haemosiderosis and renal lesions of polyarteritis nodosa with glomerular changes. Necrotizing arteritis was found in small lung arteries and in arterioles in the sciatic nerve and testicle. The fifth case was described by Soergel (1957), the patient being a girl of 13 years whose pulmonary symptoms dated from the age of 6 years. No urinary abnormalities were described during life, but at necropsy it is stated that a focal acute glomerulitis was present but no details are given. In addition three other cases have been found in which urinary abnormalities were found during life but the state of the kidneys at necropsy was not described. Waldenström's (1944) second case, a boy of 15 years, showed proteinuria, but in the necropsy report published in a separate paper by Gellerstedt (1939) there is no mention of the kidneys. The second of three cases described by Browning and Houghton (1956) showed a pronounced albuminuria, but again there is no description of the kidneys at necropsy. In the case of a 7 $7 \frac{1}{2}$-year-old boy Schuler and Flesch (1955) found red and white blood cells together with casts in the urine. At necropsy the only kidney abnormality recorded was a collection of lymphocytes in the cortex.

We have recently seen a renal and a lung biopsy from a patient with repeated haemoptysis in whom a renal lesion was present. The patient, to be described in detail by Walker and Joekes, was a young man aged 20 years who, during routine examination for the haemoptysis, was found to have proteinuria with red blood cells, white blood cells, and casts in the sediment. Renal biopsy showed a focal glomerulonephritis in which some glomeruli were normal, some showed cellular proliferation, and others were either partially or completely hyalinized. Lung biopsy showed haemosiderin-containing macrophages in alveoli.

Because of the polyarteritis nodosa in Case 1 and in the case of Bruwer et al. quoted above, the incidence of pulmonary haemorrhage was sought in cases of polyarteritis nodosa with glomerular lesions. In particular it was felt that cases of this disease with involvement of pulmonary arteries would be the most fruitful group to study. Rose and Spencer (1957) in a description of 31 patients with lung involvement made no mention of extensive haemorrhages such as are seen in the cases under discussion. Godman and Churg (1954), in a paper describing the necropsy findings in seven cases of
Wegener's granulomatosis (1939), a condition in which pulmonary arteritis and necrotizing glomerulitis are frequently found together, did not describe extensive pulmonary haemorrhage. Such haemorrhage of the lung is, however, mentioned in one of eight cases of periarteritis nodosa with lung involvement described by Sweeney and Baggenstoss (1949), but as the paper was concerned with lung changes only it is not possible to assess the condition of the kidneys. While it seems exceptional to find extensive lung haemorrhage in polyarteritis nodosa, certain solitary case reports of this association have been found. MacMahon, Derow, and Patterson (1953) described a man of 55 years who first complained of haemoptysis and then died in renal failure. The lungs showed a fulminating panarteritis of a few medium-sized vessels with capillary congestion, haemosiderosis, and induration of the lung. The kidneys showed a focal glomerulonephritis of the type seen in polyarteritis nodosa. In a clinico-pathological conference, Mendeloff and Smith (1955) described a diffuse haemosiderosis of the lungs with no vascular lesions in a 16-year-old girl, this being associated with a renal picture resembling healed focal embolic nephritis. It was suggested that the latter picture might be considered a healed form of the microscopical type of polyarteritis of Davson et al. Arteritic changes in the pancreas and adrenal supported this. A recent case of Wegener's syndrome described by Thomas (1958) concerned a 40 -year-old man who had scattered haemorrhages in the lung, areas of lung containing iron-filled macrophages, and acute arteritis in small lung blood vessels. The kidneys showed a necrotizing focal glomerulonephritis. In four of the seven cases of haemorrhagic and interstitial pneumonitis with nephritis described by Parkin et al. (1955), evidence of polyarteritis nodosa was found, but arteritic changes in the lung were found in only one case, and in that case only a solitary artery was involved. Thus it would appear that even when there is evidence of polyarteritis nodosa in a case with extensive lung haemorrhage, the latter is in all probability not caused by acute arteritis and the source of bleeding is more likely to be the alveolar capillaries or bronchopulmonary anastomoses.

The possible relationship of the lungs under discussion to the uraemic lung described by Doniach (1947) must be considered. In patients with uraemia and left ventricular failure he described lungs showing a widespread "solid oedema" due to a fibrinous or albuminous intraalveolar exudate. This was associated with a mononuclear cell reaction, organization of 
exudate, and hyaline membranes lining alveolar ducts. The exudate was considered to result from a combination of a rise in pulmonary capillary pressure due to left ventricular failure and an alteration in capillary permeability resulting from uraemia. In some of the cases red blood cells and haemosiderin-containing macrophages were found in alveoli. In the cases of the present series all had a terminal uraemia, but in only one case (No. 3) was there definite evidence of left ventricular failure. In this case there was considerably more haemorrhage and less in the nature of albuminous exudate than the usual picture described by Doniach.

Parkin et al. (1955) considered the association of pulmonary haemorrhage and an acute renal lesion explicable on a basis of hypersensitivity. They drew attention to the experiments of Cannon, Walsh, and Marshall (1941) and Gregory and Rich (1946) on anaphylactic pulmonary lesions in rabbits. These experimental lung lesions, in neither of which, it should be noted, was there much haemorrhage, were compared with the type of lung found in the human in acute rheumatism as described by Gouley and Eiman (1932) and Epstein and Greenspan (1941). The so-called rheumatic lung, it might be observed, differs in no way from the lungs described by Doniach and cannot be considered specific for a hypersensitivity state. This concept of Parkin et al. (1955) that both lung and renal lesion can be explained on a hypersensitivity basis is attractive but on the available evidence purely speculative. The renal lesion in the three cases under discussion is of essentially the same type as that described by Parkin et al. and of a type usually associated with hypersensitivity, although there is nothing in the case histories indicative of any sensitizing episode. The lung lesion differs from that in the series of Parkin et al. in that no alveolitis is present and the slight alveolar septal changes are probably a result rather than a cause of the haemorrhage. The aetiology of the lung haemorrhage must remain obscure just as in idiopathic pulmonary haemosiderosis, a condition which resembles the lungs of Cases 2 and 3 to the point of identity.

It would appear, however, from the numerous cases quoted in the discussion that there is more than a chance association of lung haemorrhage with glomerular disease, the exact relationship not being obvious.

\section{Summary}

Three patients with severe pulmonary
haemorrhage dying from renal failure are
described. In all there was an extensive

glomerular lesion, acute in two and chronic, with evidence of recent activity, in the third. In two of the cases there was a history of repeated haemoptyses whilst in the other overt haemoptysis occurred only during the last few days of life. Clinical evidence of cardiac failure was present in only one case. The pulmonary lesions resembled closely those of idiopathic pulmonary haemosiderosis and the incidence of renal involvement in that condition is described. There is little in the present series to suggest with certainty the nature of the association between the pulmonary and the renal lesion.

We are grateful to Drs. W. D. W. Brooks, T. C. Hunt, and J. W. Litchfield for permission to report on these cases, and to the technical staff of this department for the preparation of large numbers of sections.

\section{REFERENCES *}

Anspach, W. E. (1939). Amer. J. Roentgenol., 41, 592.

Borsos-Nachtnebel, Ö. (1942). Zbl. allg. Path. path. Anat., 79, 174. Browning, J. R., and Houghton, J. D. (1956). Amer. J. Med., $20,374$. Bruwer, A. J., Kennedy, R. L. J., and Edwards, J. E. (1956). Amer. J. Roentgenol., 76, 98.

Cannon, P. R., Walsh, T. E., and Marshall, C. E. (1941). Amer. J. Path., 17, 777.

Ceelen, W. (1931). In Henke, F., and Lubarsch, O., Handbuch der speziellen pathologischen Anatomie und Histologie, Vol. 3 , Pt. 3, p. 20. Springer, Berlin.

Davson, J., Ball, J., and Platt, R. (1948). Quart.J. Med. n.s. 17, 175. Doniach, I. (1947). Amer. J. Roentgenol., 58, 620.

El.is, A. (1942). Lancet, 1, 1.

Epstein, E. Z., and Greenspan, E. B. (1941). Arch. intern. Med., 68, 1074.

Gellerstedt, N. (1939). Acta path. microbiol. scand., 16, 386.

Glanzmann, E., and Walthard, B. (1941). Mschr. Kinderheilk., 88, 1. Godman, G. C., and Churg, J. (1954). A.M.A. Arch. Path., 58, 533. Gouley, B. A., and Eiman, J. (1932). Amer. J. med. Sci., 183, 359. Gregory, J. E., and Rich, A. R. (1946). Bull. Johns Hopk. Hosp., 78,1 .

Halmágyi, D., Felkai, B., Sövényi, E., Weber, A., Czipott, Z., Kovács, G., and Steiner, B. (1956). Z Z. Kreisl.-Forsch., 45, 40,

Lendrum, A. C., Scott, L. D. W., and Park, S. D. S. (1950). Quart. J. Med., n.s. 19, 249.

MacMahon, H. E., Derow, H. A., and Patterson, J. F. (1953). Bull. New Engl. med. Cent., 15, 161.

Mendeloff, A. I., and Smith D. E. (1955). Amer. J. Med., 18, 335.

Parkin, T. W. Rusted, I. E., Burchell, H. B., and Edwards, J. E. (1955). Ibid., 18, 220.

Propst, A. (1955). Virchows Arch. path. Anat., 326, 633.

Rose, G. A., and Spencer, H. (1957). Quart. J. Med., n.s. 26, 43.

Russi, S., and Wingo, C. F. (1956). Amer. J. Path., 32, 611.

Scheidegger, S., and Dreyfus, A. (1945). Ann. paediat. (Basel), 165, 2. Schuler, D., and Flesch, I. (1955). Ibid., 185, 96.

Soergel, K. H. (1957). Pediatrics, 19, 1101.

Sweeney, A. R., Jr., and Baggenstoss, A. H. (1949). Proc. Mayo Clin., 24,35 .

Tait, G. B. and Corridan, M. (1952). Thorax, 7, 302.

Thomas, A. M. (1958). J. clin. Path., 11, 146.

Volhard, F., and Fahr, T. (1914). Die Brightsche Nierenkrankheit. Springer, Berlin.

Waldenström, J. (1944). Acta radiol. (Stockh.), 25, 149.

Walker, J. R., and Joekes, A. M. To be published.

Wegener, F. (1939). Beitr. path. Anat., 102, 36.

* The authors have reviewed all the published cases of idiopathic pulmonary haemosiderosis. but only the strictly pertinent papers have been quoted. 